\title{
IMPROVEMENT IN REAL TIME DETECTION AND SELECTIVITY OF PHTHALOCYANINE GAS SENSORS DEDICATED TO OXIDIZING POLLUTANTS EVALUATION.
}

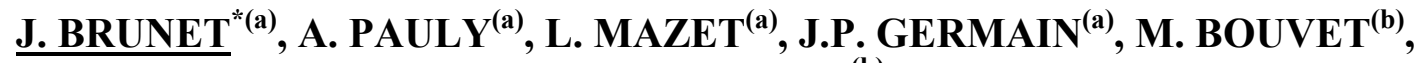 \\ B. MALEZIEUX ${ }^{(\mathbf{b})}$ \\ (a) :LASMEA (UMR 6602 du CNRS), Université Blaise Pascal, CLERMONT-FERRAND II, \\ 24, Avenue des Landais 63177 AUBIERE Cedex, France. \\ (b) :CIM², Université Pierre et Marie Curie, PARIS, 4, Place Jussieu 75252 PARIS Cedex 05, \\ France.
}

\begin{abstract}
A sensor microsystem prototype, using copper phthalocyanine thin film as sensitive layer, and dedicated to ozone evaluation, was developed. The methodology implemented is based on cyclic sensor recalibrations by thermal cleaning of the sensitive membrane, and on pollutant concentration quantification according to the kinetics of sensor response. Results of laboratory experiments for various $\mathrm{NO}_{2}$ and $\mathrm{O}_{3}$ concentrations, in the range of 10-200 ppb, illustrate the selectivity of $\mathrm{CuPc}$ sensors towards ozone, obtained by our methodology. We have shown that ozone selectivity is especially improved for short time of exposure (few minutes) and for phthalocyanine layer maintained at low temperature $\left(80^{\circ} \mathrm{C}\right)$. For optimal conditions, our microsytem exhibits a threshold lower than $10 \mathrm{ppb}$, a resolution lower than 10 ppb, and good reproducibility of measurements. Performances obtained in real urban atmosphere are satisfying to ensure real time evaluation of ozone during several days. Longterm stability and the detection of $\mathrm{NO}_{2}$ by associating chemical filters to our microsystem will be also discussed.
\end{abstract}

Keywords: phthalocyanine, ozone, nitrogen dioxide, gas sensors, real time detection.

* Corresponding author. Tel : 33-473-407451; Fax : 33-473-407262

E-mail : brunet@lasmea.univ-bpclermont.fr 


\section{Introduction.}

To ensure pollutant concentration monitoring in atmosphere, air quality control networks commonly used commercial gas analyzers which principle of measurement is based on spectroscopic analysis. Despite of their good performances, their high cost and their uneasy implementation remain them unadapted for sporadic campaigns of measurement or to realize a cartography of pollution with high spatial resolution. On the other hand, for such application, chemical gas sensors are very attractive but need to have optimum metrological characteristics, close to ideal ones.

Amongst all potential materials studied in the past to develop sensors dedicated to gaseous pollutants detection, we can mention at first solid electrolytes. Many electrolytes have been investigated for the detection of $\mathrm{NO}[1-3], \mathrm{NO}_{2}$ [4-7] and $\mathrm{O}_{3}[8,9]$. Nevertheless, such devices often work at high temperatures and exhibit detection thresholds larger than pollutant concentrations range in urban atmosphere. The second class of materials massively investigated is metallic oxides : $\mathrm{SnO}_{2}$, doped or undoped, towards $\mathrm{CO}[10,11], \mathrm{NO}_{\mathrm{x}}[11], \mathrm{O}_{3}$ [12] or Volatil Organic Compounds [10]; $\mathrm{In}_{2} \mathrm{O}_{3}$ towards $\mathrm{CO}$ [13], $\mathrm{NO}_{2}[14,15], \mathrm{O}_{3}[16,17]$ or CH4 [18]; and $\mathrm{WO}_{3}$ towards $\mathrm{NO}_{x}[19-21]$ or $\mathrm{O}_{3}$ [21]. Although their satisfying sensitivity and reproducible results, they suffer from a lack of selectivity.

The great reactivity of phthalocyanines towards oxidizing species induced many studies on sensors using those molecular semiconductors as sensitive elements. Metallophthalocyanines have exhibited high sensitivity towards weak concentrations of $\mathrm{NO}_{2}$ $[22,23]$, good potentialities for detection of ozone [24] or even potentialities to detect VOCs $[25,26]$. But, phthalocyanines based sensors suffer from a lack of selectivity, from too slow kinetics of response, due especially to diffusion process of gaseous molecules into the layer, and from long term stability problems.

As summarized above, whatever material, metrological characteristics of chemical sensors need to be improved to become competitive with gas analyzers. Thus, different 
solutions have been investigated. The first consists in changing material by the addition of catalytic elements, as for metallic oxides [18,19,27], or by the modification of layer morphology as a result of deposition process and post-deposition treatments, as for phthalocyanines [28]. Optimization of working conditions, like temperature $[15,29]$, is the second way to reach optimal detection. The third solution consists in developing adapted methodologies of measurement, as previously studied for tin dioxide gas sensors [10] or for phthalocyanine gas sensors towards $\mathrm{NO}_{2}[30,31]$ and $\mathrm{O}_{3}$ [32].

This article deals with an original methodology of measurement which improves simultaneously selectivity and response time of phthalocyanine gas sensors dedicated to ozone. We illustrate improvements induced by results of laboratory experiments but also in urban atmosphere context.

\section{Experimental details.}

Fig.1 represents experimental apparatus developed for sensors exposure under ozone and nitrogen dioxide at very low concentrations. We can distinguish three parts which will be described in details thereafter: phthalocyanine gas sensor ; electronic unity associated including temperature regulator, polarization source and acquisition system ; and fluid circuit including mass flow controllers, cell of exposure and analyzers.

Sensitive layers of chemical sensors are constituted by thin films $(300 \mathrm{~nm})$ of copper phthalocyanine $(\mathrm{CuPc})$, purified and sublimed by thermal evaporation under vacuum (at approximately $2.10^{-6}$ torr) and deposited onto interdigitated electrodes screen-printed on the upper side of alumina substrates. During deposition, evaporation rate was $0.2 \mathrm{~nm} / \mathrm{s}$, substrates were maintained at room temperature and no consecutive thermal annealing after deposition was realized. On the lower side of the substrates, a screen-printed platinum resistor, with welldefined thermal coefficient, is devoted to sensor temperature control. Surface area of devices is 15 millimetres square and the thickness, $0.3 \mathrm{~mm}$. 
Interdigitated electrodes, polarized under $1 \mathrm{~V}$ d.c., are used to measure conductivity variations of copper phthalocyanine thin films, which depend in time of gas concentration in sensor environment. Current delivered by the structure and linked to conductivity variations, is then transformed into voltage by current-voltage converters before being recorded by a KEITHLEY digital multimeter / data acquisition system, acquisition frequency being controlled by internal clock or external trigger. Data are then transferred by RS232 serial link to one computer to be easily treated. A temperature regulator, including heating resistor of substrates as a part of Wheatstone bridge and controlling the equilibrium point of this bridge, permits to realize experiments at various temperatures, in the range between room temperature and $200^{\circ} \mathrm{C}$. Moreover, an internal relay controlled by an external signal (5V) permits to switch over with short delay between two different working temperatures.

Fluid circuit can be divided in three parts : measuring cell, dilution system of pollutants and gas concentration certification part. For exposure to gaseous molecules like $\mathrm{NO}_{2}$ and $\mathrm{O}_{3}$, sensors are placed into one cell made in PTFE, this material being also used for gas pipes constituting fluid circuit, because of its good chemical inertia towards strong oxidizing species. Moreover, to reduce $\mathrm{NO}_{2}$ and $\mathrm{O}_{3}$ adsorption onto inner surfaces during experiments, gas pipes and measuring cell without sensor, are previously exposed to high concentration of gas (several hundred ppb) during several hours before the first test. For laboratory experiments, $\mathrm{NO}_{2}$ is delivered by commercial and well-calibrated cylinders whereas ozone is delivered by an internal generator located inside a commercial ozone analyzer. To obtain weak pollutant concentrations, in the range of those measured in urban atmosphere, mass flow controllers driven by computer are used to dilute doping gases in purified air, i.e. atmospheric air cleaned up through charcoal and then dried through silica gel desiccant crystals. During each experiment, gas flow is maintained at $45 \mathrm{l} / \mathrm{h}$ and reliable concentrations range is between 20 and $200 \mathrm{ppb}$. To certify gas concentrations near the sensitive elements, commercial gas analyzers are linked to measuring cell output. Thus, $\mathrm{NO}_{2}$ 
concentration is quantified by a chemiluminescent nitrogen oxide analyzer (model AC32M, Environnement S.A.) and $\mathrm{O}_{3}$ concentration, by an ultraviolet photometric ozone monitor (model O341M, Environnement S.A.).

\section{Results.}

\subsection{Gas-phthalocyanine interactions : comparisons between $\mathrm{O}_{3}$ and $\mathrm{NO}_{2}$.}

The great reactivity of copper phthalocyanine with nitrogen dioxide, even in low concentrations, is well-established and has been already published [30,33,34]. Conductivity of this molecular semiconductor increases in the presence of $\mathrm{NO}_{2}$ molecules, this variation being reversible under clean air. In the past, a model has been developed to describe interactions between oxidizing species, as $\mathrm{O}_{2}$ or $\mathrm{NO}_{2}$, and phthalocyanine molecular units [35].

Fig. 2 represents conductivity versus time of $\mathrm{CuPc}$ thin film $(300 \mathrm{~nm})$, maintained at $50^{\circ} \mathrm{C}$, during one hour of exposure to oxidizing gases, and followed by one hour under purified air. We can thus compare experimental results obtained for $100 \mathrm{ppb}$ of ozone and for $100 \mathrm{ppb}$ of nitrogen dioxide, in the same operating conditions. Please notice that experiments have been realized successively on the same $\mathrm{CuPc}$ layer, the sensor being maintained at $50^{\circ} \mathrm{C}$ under clean air between each test. These curves exhibit that both $\mathrm{NO}_{2}$ and $\mathrm{O}_{3}$ induce an increase in conductivity and that sensor sensitivity is high, even for weak concentrations. Quantitatively, conductivity during one hour of exposure increases about $40 \%$ for $100 \mathrm{ppb}$ of $\mathrm{NO}_{2}$ and about $30 \%$ for $100 \mathrm{ppb}$ of $\mathrm{O}_{3}$. Kinetics of response remain slow because conductivity after one hour under gases never reaches a stable value. Nevertheless, by extrapolation, we can see that conductivity variations determined at thermodynamical equilibrium, will be higher for $\mathrm{NO}_{2}$ than $\mathrm{O}_{3}$. Considering that ozone is the more oxidizing specie, and that the stronger oxidizing the gas is, the more sensitive the phthalocyanine layer is [37], comparison of sensor response shows that interaction processes between $\mathrm{O}_{3}$ and $\mathrm{CuPc}$ can not be similar to those which occur with $\mathrm{NO}_{2}$. 
As for nitrogen dioxide, we can suppose that the first interaction process is $\mathrm{O}_{3}$ molecules adsorption onto phthalocyanine layer surface, followed by charge transfer to form $\mathrm{O}_{3}^{-}$, as already observed at low temperature on $\mathrm{CeO}_{2}$ [38]. But, $\mathrm{O}_{3}^{-}$anions being chemically unstable, their dissociation into oxygen species $\mathrm{O}^{-}$and $\mathrm{O}_{2}^{-}$is highly probable. Moreover, slow kinetics of response indicate that action of ozone on phthalocyanine is not only a surface adsorption process but also implies diffusion process of gaseous species toward active sites located in the bulk of the layer. Because of their chemical unstability, $\mathrm{O}_{3}$ molecules have only a very weak probability to diffuse into the volume, as compared to $\mathrm{O}$ and $\mathrm{O}_{2}$ molecules. Oxygen species having lower electronic affinities than $\mathrm{NO}_{2}$ [14], charge transfer, which occurs consecutively to diffusion, is less efficient. That's the reason why for long time of exposure ( $>1$ hour), i.e. when diffusion process is not negligible, conductivity variations measured under $\mathrm{O}_{3}$ are lower than for the same concentration of $\mathrm{NO}_{2}$, although ozone oxidizing power is stronger.

As illustrated by fig. 2, we can also notice that for short times of exposure, in order of few minutes, kinetics of response are faster for $\mathrm{O}_{3}$. In such conditions, conductivity variations induced by ozone is then higher than for the same concentration of $\mathrm{NO}_{2}$. Thus, by exploiting kinetics of reaction between gases and phthalocyanines, it seems possible to reach fast ozone concentration determination, even with the presence of $\mathrm{NO}_{2}$.

\subsection{Improvements of sensing characteristics : towards a real time detection of $\mathrm{O}_{3}$ in}

air.

To achieve selective evaluation of ozone and to solve problems due to the too long response time phthalocyanine sensors suffer, we have developed a methodology of measurement based on response kinetics study of sensors exposed during short times under pollutants. Moreover, to avoid drift problems due to slow process of desorption, i.e. to improve reproducibility of results, consecutively to each measurement, sensitive layer is 
regenerated under purified air at high temperature. Fig. 3 represents conductivity versus time of copper phthalocyanine thin film during two cycles of measurement by our methodology. We can distinguish 3 steps :

- I : thermal cleaning of sensitive layer at $160^{\circ} \mathrm{C}$ under purified air during 10 minutes. It corresponds to $\mathrm{CuPc}$ thin film regeneration before the next measurement under pollutant. Semiconductor conductivity firstly increases because of charge carriers creation by thermal activation (semiconductor effect) and secondly decreases, due to the annihilation of extrinsic carriers induced by gaseous molecules desorption from the surface and from the bulk of the layer.

- $\quad$ II : stabilization of sensor signal under purified air at working temperature, i.e. $80^{\circ} \mathrm{C}$, during 1 minute. Conductivity decrease is due to the annihilation of carriers, induced by negative gradient of temperature. At the end of this step, which corresponds to the reach of a stable conductivity, is determined the initial conductivity under clean air, $\sigma_{\mathbf{i}}$.

- III : exposure of sensor, maintained at $80^{\circ} \mathrm{C}$ to pollutants during 4 minutes. Conductivity increase can be explained by extrinsic charge carriers creation into the molecular semiconductor by oxydoreduction reactions with $\mathrm{O}_{3}$ or $\mathrm{NO}_{2}$. At the end of sensor submission is determined $\sigma_{\mathbf{f}}$, final conductivity under pollutants at working temperature.

The time of one cycle of measurement is 15 minutes and sensor response by our methodology is then defined as $\sigma_{\mathbf{f}}-\sigma_{\mathbf{i}}$. Please notice that experimental results have show only a weak dispersion of $\sigma_{\mathbf{i}}$, even during long periods of repetitive tests, without any consequence on sensor response.

Fig. 4 represents response of $\mathrm{CuPc}$ thin film associated to our methodology previously described, versus time, for various concentrations of $\mathrm{O}_{3}$, in the range 50-200 ppb. Time between two results corresponds to the time of one cycle, i.e. 15 minutes. At first, this result 
shows that response is a function of $\mathrm{O}_{3}$ concentration and that sensitivity remains high for weak concentrations. In example, for $100 \mathrm{ppb}$ of ozone, relative variations of conductivity, defined as $\left(\sigma_{\mathbf{f}}-\sigma_{\mathbf{i}}\right) / \sigma_{\mathbf{i}}$, is approximately $600 \%$. Moreover, if we compare responses for increasing concentrations, results appear reproducible. It illustrates that desorption process is efficient. But, let us notice that drift of response for the first submissions to ozone is due to adsorption process onto inner surfaces of measuring cell and gas pipes, as confirmed by data of analyzer located at the output of fluid circuit.

To emphasize selectivity improvements toward ozone induced by our methodology, fig. 5 represents responses of $\mathrm{CuPc}$ sensor associated to our methodology towards different concentrations of $\mathrm{O}_{3}(\cdot)$ and $\mathrm{NO}_{2}(+)$, in the range of those measured in urban atmosphere, i.e. 20-200 ppb. For each concentration, 3 consecutive cycles of measurement were realized. These curves highlight:

- $\quad$ the good reproducibility of results, illustrated by the weak dispersion of experimental points relative to one gas at one concentration,

- $\quad$ the low threshold of detection (under $20 \mathrm{ppb}$ ),

- $\quad$ the good resolution, especially for ozone (under $10 \mathrm{ppb}$ ),

- $\quad$ the greater sensitivity for $\mathrm{O}_{3}$. To compare, relative variations of conductivity $\left(\left\{\sigma_{\mathbf{f}}-\sigma_{\mathbf{i}}\right\} /\right.$ $\left.\sigma_{\mathrm{i}}\right)$ to $100 \mathrm{ppb}$ is approximately $600 \%$ for $\mathrm{O}_{3}$ and $80 \%$ for $\mathrm{NO}_{2}$. Moreover, conductivity variations measured for $20 \mathrm{ppb}$ of ozone is 3 time greater than conductivity variations relative to $100 \mathrm{ppb}$ of nitrogen dioxide.

In atmosphere where those two species coexist, sensor signal shouldn't be highly affected by $\mathrm{NO}_{2}$ concentration variations. Thus, in view of results, this methodology appears very attractive to improve performances of phthalocyanine gas sensors for a real time and selective quantification of ozone in troposphere where oxidizing gases rarely exceed studied concentration range. 


\subsection{Performances in urban air context.}

To validate experimental results obtained at laboratory, we have developed a sensor microsystem prototype, exploiting our methodology of measurement, which has been placed several days in one station of air quality control of the local network of pollution monitoring in Clermont-Ferrand (FRANCE). Fig 6. represents response delivered by our microsystem during 3 days, compared with ozone and nitrogen dioxide concentrations measured by commercial analyzers located in the same monitoring station. The time between two measurements is the same for all devices and is 15 minutes. These curves show a strong correlation between conductivity variations delivered by $\mathrm{CuPc}$-based gas sensor and $\mathrm{O}_{3}$ concentration. Thus, our sensor microsystem is very sensitive to high variations of ozone concentration (part A) but also to weak evolutions, even when variations are equal to 10 $\mu$ g. $\mathrm{m}^{-3}$, i.e. approximately $5 \mathrm{ppb}$ (part B). This illustrates the good resolution of our sensor microsystem.

Moreover, we can see on fig. 6 that nitrogen dioxide seems not to affect sensor microsystem response. Indeed, as illustrated on the part $\mathrm{C}$ of these curves, although $\mathrm{NO}_{2}$ concentration strongly increases and in the same time $\mathrm{O}_{3}$ rate decreases, microsystem response remains correlated with ozone variations. Thus, experiments in outdoor conditions confirm partial selectivity towards $\mathrm{O}_{3}$ induced by our methodology.

\section{Discussion.}

Neither results of laboratory experiments illustrated by fig. 4 and fig. 5 , nor results in outdoor conditions during 3 days as shown by fig. 6, are sufficient to conclude on long-term stability and to evaluate lifetime. To study long term effects of ozone exposures on copper phthalocyanine sensors, many successive cycles of sorption/desorption have been realized at laboratory at low temperature. We have noticed a slow drift of sensor responses towards ozone with time, which corresponds to irreversible decrease in initial conductivity under 
purified air and in sensor sensitivity. Such degradations have been also observed on response to $\mathrm{NO}_{2}$, especially when between each exposure, sensor has been submitted to ozone treatments. These effects are interpreted as slow and irreversible oxidation of phthalocyanine macrocycles by ozone molecules, firstly on the surface, secondly into the bulk. Indeed, $\mathrm{O}_{3}$ is greatly reactive with carbon double-bonds, inducing the $\mathrm{C}-\mathrm{C}$ bonds dissociation in particular conditions. So, ozone can chemically react with carbon double-bonds of phthalocyanine macrocyles [24]. Thus, active sites number decreases firstly at the surface and secondly into the volume, inducing increase in resistance of the sensitive layer and simultaneously, decrease in sensitivity towards oxidizing gases, as observed during laboratory experiments.

In outdoor conditions, a slow poisonous effect of sensitive layer by ozone has been also noticed after several days of continuous use, illustrated by similar degradation of sensing characteristics, i.e. decrease in average conductivity and in sensitivity. Despite of the short time of sensor exposure to ozone during one cycle of measurement by our methodology, irreversible oxidation remains unavoidable and reduces lifetime of sensitive element, which can be estimated in such conditions to one month.

If good improvements have been obtained by our sensor microsystem to reach selective detection in real time of ozone in atmosphere, this device is not restricted to this gas. We could imagine to detect similarly $\mathrm{NO}_{2}$ with identical sensing performances. In this case, in view of long-term degradation phenomenon induced by ozone, it becomes necessary to eliminate this gas into fluidic circuit, using selective filters. Different materials have been investigated but an organic stain, indigo, seems very attractive. First laboratory experiments made to evaluate indigo as filter show that it removes completely ozone without removing $\mathrm{NO}_{2}$, until 1 ppm during 90 hours. Experiments realized in outdoor conditions with indigo filter associated with $\mathrm{CuPc}$ sensor show that sensor signal is greatly correlated with $\mathrm{NO}_{2}$ concentration variations, during several days, even when $\mathrm{O}_{3}$ average concentration is simultaneously higher. Measurements with this promising filter associated to our sensor 
microsystem should be tested in well and non controlled atmospheres. Moreover, the simultaneous quantification of $\mathrm{NO}_{2}$ and $\mathrm{O}_{3}$ could be realized by our microsystem with sequential filtering of ozone by indigo filter half the time. Thus, in such conditions, $\mathrm{NO}_{2}$ and $\mathrm{O}_{3}$ concentrations could be determined each 30 minutes. Nevertheless, premature ageing of phthalocyanines remains a major problem.

\section{Conclusion}

CuPc-based sensor is one potential device which could be used as oxidizing pollutants detectors. But, too long response time, due to slow diffusion process into the sensitive layer, and the lack of selectivity, were two damaging factors for such application. Comparison between CuPc-based sensor responses towards $\mathrm{O}_{3}$ and $\mathrm{NO}_{2}$ shows that for short times of exposure (few minutes), kinetics of response are in favour of $\mathrm{O}_{3}$, inducing higher conductivity variations than those measured during the same time, for the same concentration of $\mathrm{NO}_{2}$.

The original methodology of measurement we have developed, based on gas concentration determination according to the kinetics of sensor response, and cyclic recalibration of sensor by thermal cleaning, permits to greatly improve metrological characteristics. Thus, such apparatus permit to quantify selectively $\mathrm{O}_{3}$ in atmosphere, with a high sensitivity, a threshold and a resolution inferior to $10 \mathrm{ppb}$, and in real time. Measurement campaigns made in urban atmosphere illustrate that response delivered by our sensor microsystem is highly correlated to $\mathrm{O}_{3}$ concentration variations recorded by ultraviolet photometric ozone analyzer. Lifetime of sensor is limited by irreversible oxidation of phthalocyanine molecules by ozone and mainly, by the slow degradation of molecular units into the bulk of the layer. But, for $300 \mathrm{~nm}$ copper phthalocyanine film, it can be estimated to several days for continuous use in outdoor conditions.

Our sensor microsystem is not restricted to ozone quantification. To evaluate similarly $\mathrm{NO}_{2}$ rate, one ought to place at the fluid circuit input, an $\mathrm{O}_{3}$ selective chemical filter. For such 
application, in view of its ability to completely eliminate $\mathrm{O}_{3}$ without destroying $\mathrm{NO}_{2}$, indigo is a very attractive and promising material, as confirmed by laboratory and outdoor experiments. 


\section{References}

[1] N. Miura, G. Lu, N. Yamazoe, Sensors and Actuators B 52 (1998) 169-178.

[2] Y. Shimizu, K. Maeda, Sensors and Actuators B 52 (1998) 84-89.

[3] S. Zhuiykov, T. Nakano, A. Kunimoto, N. Yamazoe, N. Miura, Electrochemistry Communications 3 (2001) 97-101.

[4] N. Miura, M. Ono, K. Shimanoe, N. Yamazoe, Sensors and Actuators B 49 (1998) 101109.

[5] J.F. Currie, A. Essalik, J-C. Marusic, Sensors and Actuators B 59 (1999) 235-241.

[6] P. Hrncirova, F. Opekar, K. Stulik, Sensors and Actuators B 69 (2000) 199-204.

[7] J.W. Yoon, M.L. Grilli, E. Di Bartolomeo, R. Polini, E. Traversa, Sensors and Actuators B 76 (2001) 483-488.

[8] L. Xie, J. Lu, H. Yan, Electroanalysis 10 (1998) 842-845.

[9] R. Knake, P.C. Hauser, Analytica Chimica Acta 459 (2002) 199-207.

[10] S. Nicoletti, L. Dori, G.C. Cardinali, A. Parisini, Sensors and Actuators B 60 (1999) 9096.

[11] C. Pijolat, C. Pupier, M. Sauvan, G. Tournier, R. Lalauze, Sensors and Actuators B 59 (1999) 195-202.

[12] T. Becker, L. Tomasi, C. Bosch-v.Braunmühl, G. Müller, G. Sberveglieri, G. Fagli, E. Comini, Sensors and Actuators A 74 (1999) 229-232.

[13] W-Y. Chung, G. Sakai, K. Shimanoe, N. Miura, D-D. Lee, N. Yamazoe, Sensors and Actuators B 65 (2000) 312-315.

[14] A. Gurlo, N. Barsan, M. Ivanovskaya, U. Weimar, W. Göpel, Sensors and Actuators B 47 (1998) 92-99.

[15] M. Ivanovskaya, A. Gurlo, P. Bogdanov, Sensors and Actuators B 77 (2001) 264-267.

[16] T. Doll, A. Fuchs, I. Eisele, G. Faglia, S. Gropelli, G. Sberveglieri, Sensors and Actuators B 49 (1998) 63-67.

[17] S-R. Kim, H.K. Hong, C.H. Know, D.H. Yun, K. Lee, Y.K. Sung, Sensors and Actuators B 66 (2000) 59-62.

[18] S.N. Malchenko, Y.N. Lychkovsky, M.V. Baykov, Sensors and Actuators B 13-14 (1993) 159-161.

[19] M. Penza, C. Martucci, G. Cassano, Sensors and Actuators B 50 (1998) 52-59. 
[20] W. Zhang, H. Uchida, T. Katsube, T. Nakatsubo, Y. Nishioka, Sensors and Actuators B 49 (1998) 58-62.

[21] C. Cantalini, W. Wlodarski, Y. Li, M. Passacantando, S. Santucci, E. Comini, G. Faglia, G. Sberveglieri, Sensors and Actuators B 64 (2000) 182-188.

[22] T.A. Jones, B. Bott, Sensors and Actuators B 9 (1986) 27-37.

[23] A. Heilmann, V. Lantto, M. Müller, C. Hamann, Sensors and Actuators B 7 (1992) 522525.

[24] M. Bouvet, A. Leroy, J. Simon, F. Tournilhac, G. Guillaud, P. Lessnick, A. Maillard, S. Spirkovitch, M. Debliquy, A. de Haan, A. Decroly, Sensors and Actuators B 72 (2001) 86-93.

[25] M.L. Rodriguez-Mendez, J. Souto, R. de Saja, J. Martinez, J.A. de Saja, Sensors and Actuators B 58 (1999) 544-551.

[26] C. Fietzek, K. Bodenhöfer, M. Hees, P. Haisch, M. Hanack, W. Göpel, Sensors and Actuators B 65 (2000) 85-87.

[27] M. Fleischer, S. Kornely, T. Weh, J. Frank, H. Meixner, Sensors and Actuators B 69 (2000) 205-210.

[28] Y-L. Lee, W-C Tsai, C-H Chang, Y-M. Yang, Applied Surface Science 172 (2001) 191199.

[29] L.E. Depero, M. Ferroni, V. Guidi, G. Marca, G. Martinelli, P. Nelli, L. Sangaletti, G. Sberveglieri, Sensors and Actuators B 35-36 (1996) 381-383.

[30] C. Park, D.H. Yun, S-T. Kim, Y.W. Park, Sensors and Actuators B 30 (1996) 23-27.

[31] M.I. Newton, T.K.H. Starke, M.R. Willis, G. McHale, Sensors and Actuators B 67 (2000) 307-311.

[32] A. Schütze, N. Pieper, J. Zacheja, Sensors and Actuators B 23 (1995) 215-217.

[33] S. Dogo, J.P. Germain, C. Maleysson, A. Pauly, Thin Solid Films 219 (1992) 251-256.

[34] M. Masui, M. Sasahara, T. Wada, M. Takeuchi, Applied Surface Science 92 (1996) 643646.

[35] M. Passard, A. Pauly, J.P. Blanc, S. Dogo, J.P. Germain, C. Maleysson, Thin Solid Films 237 (1994) 272-276.

[36] J. Brunet, L. Talazac, V. Battut, A. Pauly, J.P. Blanc, J.P. Germain, S. Pellier, C. Soulier, Thin Solid Films 391 (2001) 308-313.

[37] A. Pauly, J-P. Germain, J-P. Blanc, Electron Technology 33 (2000) 179-186. 
[38] A. Naydenov, R. Stoyanova, D. Mehandjiev, Journal of Molecular Catalysis A chemical 98 (1995) 9-14. 


\section{Figure captions}

Fig. 1 : Experimental apparatus for laboratory measurements under weak concentrations of nitrogen dioxide and ozone in air.

Fig. 2 : Conductivity variations versus time of CuPc-based sensors maintained at low temperature $\left(50^{\circ} \mathrm{C}\right)$, induced by exposure to $100 \mathrm{ppb}$ of $\mathrm{NO}_{2}(+++)$ and $100 \mathrm{ppb}$ of $\mathrm{O}_{3}(-)$, following by return under clean air. A : introduction of oxidizing gas in measuring cell; $\mathbf{B}$ : beginning of desorption process under clean air.

Fig. 3 : Conductivity of $\mathrm{CuPc}$ thin film versus time during two cycles of measurement by our methodology. One cycle can be dissociated in three steps. Step I : regeneration of sensitive layer at high temperature $\left(160^{\circ} \mathrm{C}\right)$ under clean air; Step II : stabilization of sensor signal at working temperature $\left(80^{\circ} \mathrm{C}\right)$ under clean air; Step III : exposure of sensor to pollutants at working temperature $\left(80^{\circ} \mathrm{C}\right)$. Response is thus defined by the difference $\sigma_{\mathbf{f}}-\sigma_{\mathbf{i}}, \sigma_{\mathbf{i}}$ being initial conductivity at the end of stabilization step and $\sigma_{\mathbf{f}}$, conductivity value at the end of exposure period to pollutants.

Fig. 4: Response of CuPc-based sensor associated to the methodology of measurement towards different concentrations of ozone between 50 and $200 \mathrm{ppb}$. For each concentration, 3 cycles of measurements are realized and illustrate the good reproducibility of results.

Fig. 5 : Comparison of responses delivered by CuPc-based sensor associated with our methodology towards different concentrations of $\mathrm{NO}_{2}(\bullet)$ and $\mathrm{O}_{3}(+)$. For each concentration, 3 cycles of measurement are realized. 
Fig. 6: Comparison between response delivered by CuPc-based sensor associated to our methodology of measurement and oxidizing pollutant concentrations $\left(\mathrm{NO}_{2}\right.$ and $\left.\mathrm{O}_{3}\right)$ measured by commercial analyzers, in urban air context, during 3 days. Experiments are realized in one station of pollution monitoring, in the centre of Clermont-Ferrand, and data are delivered by the local network of air quality control, AtMO AUVERGNE. 


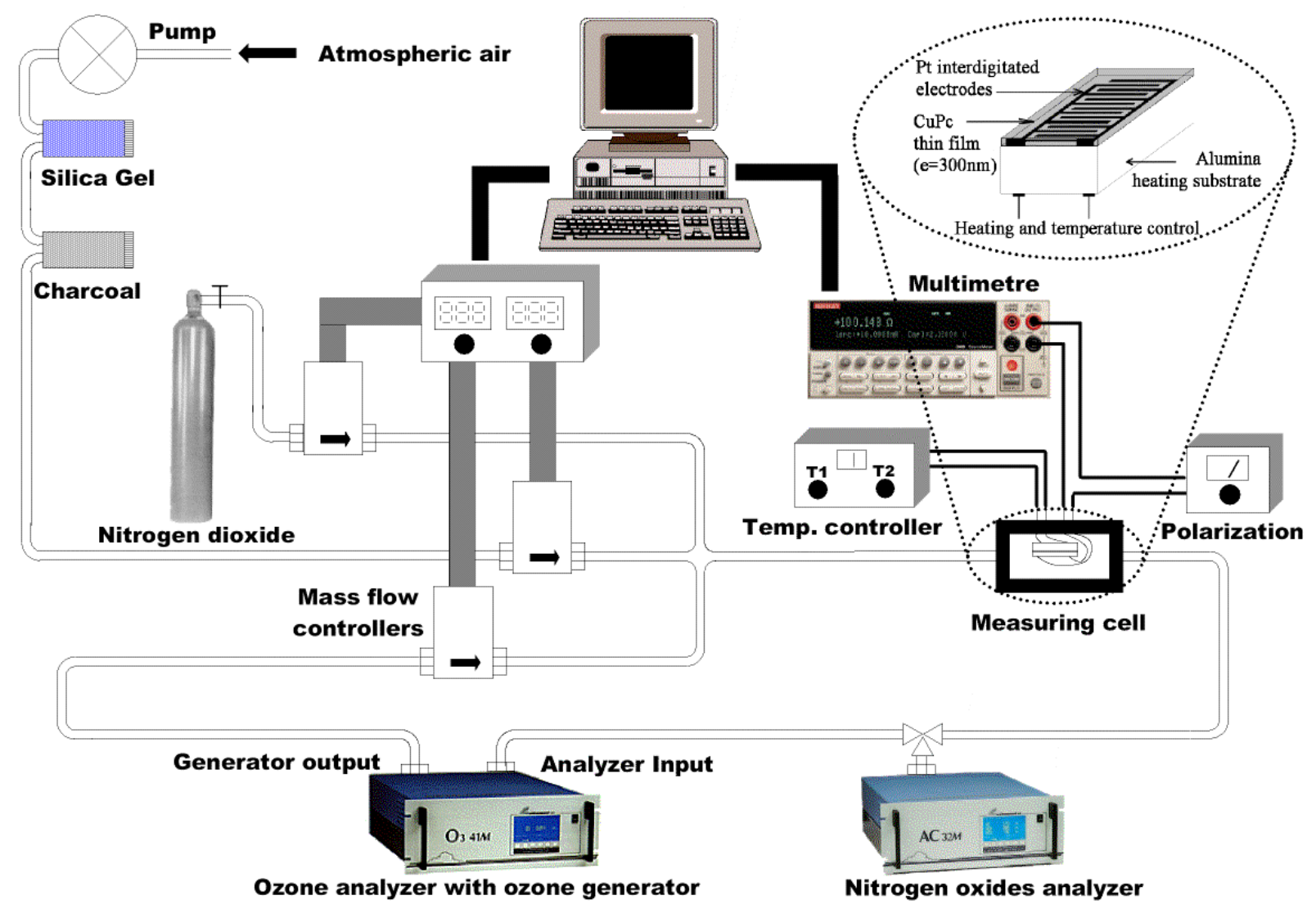

Fig. 1. 


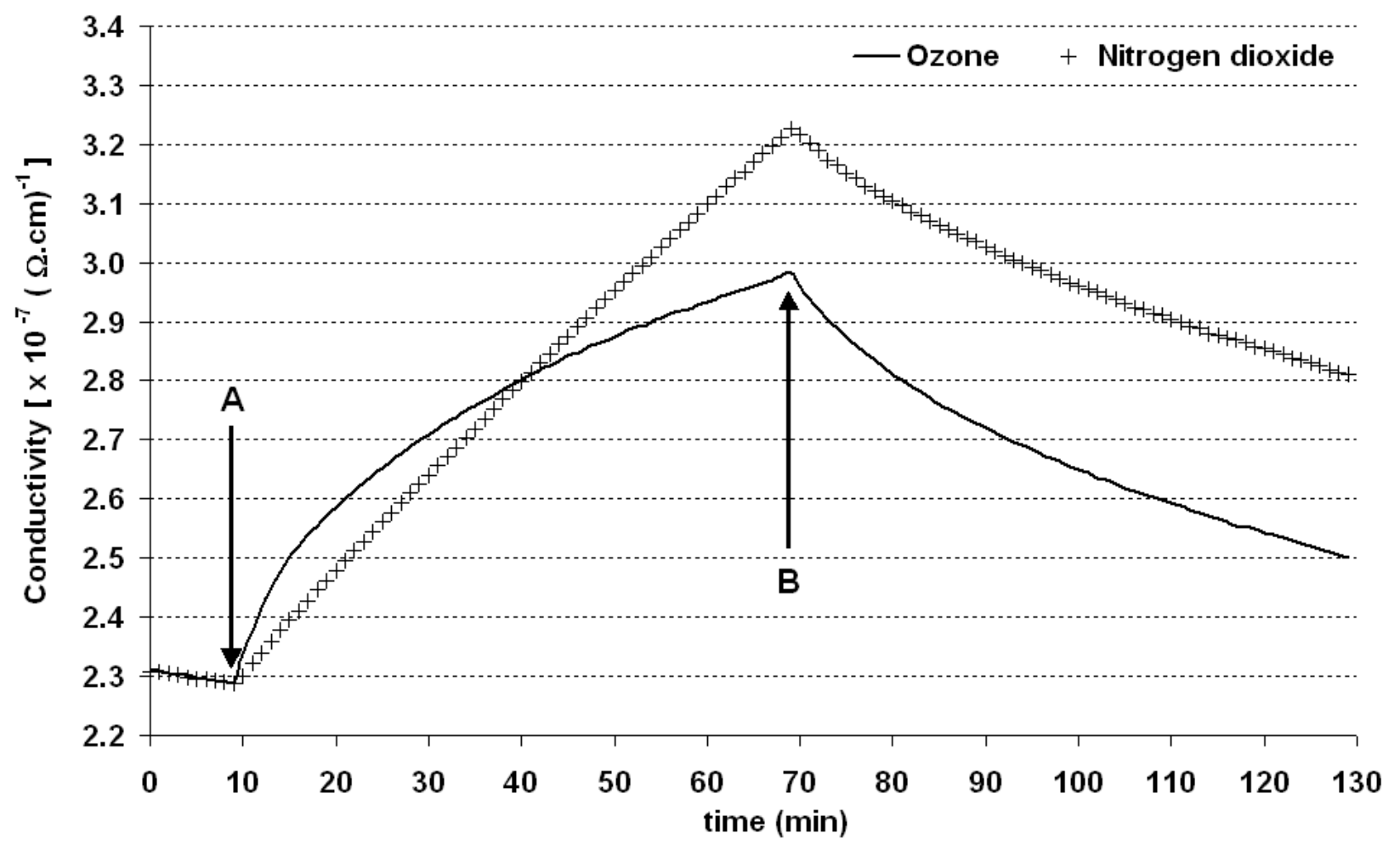

Fig. 2. 


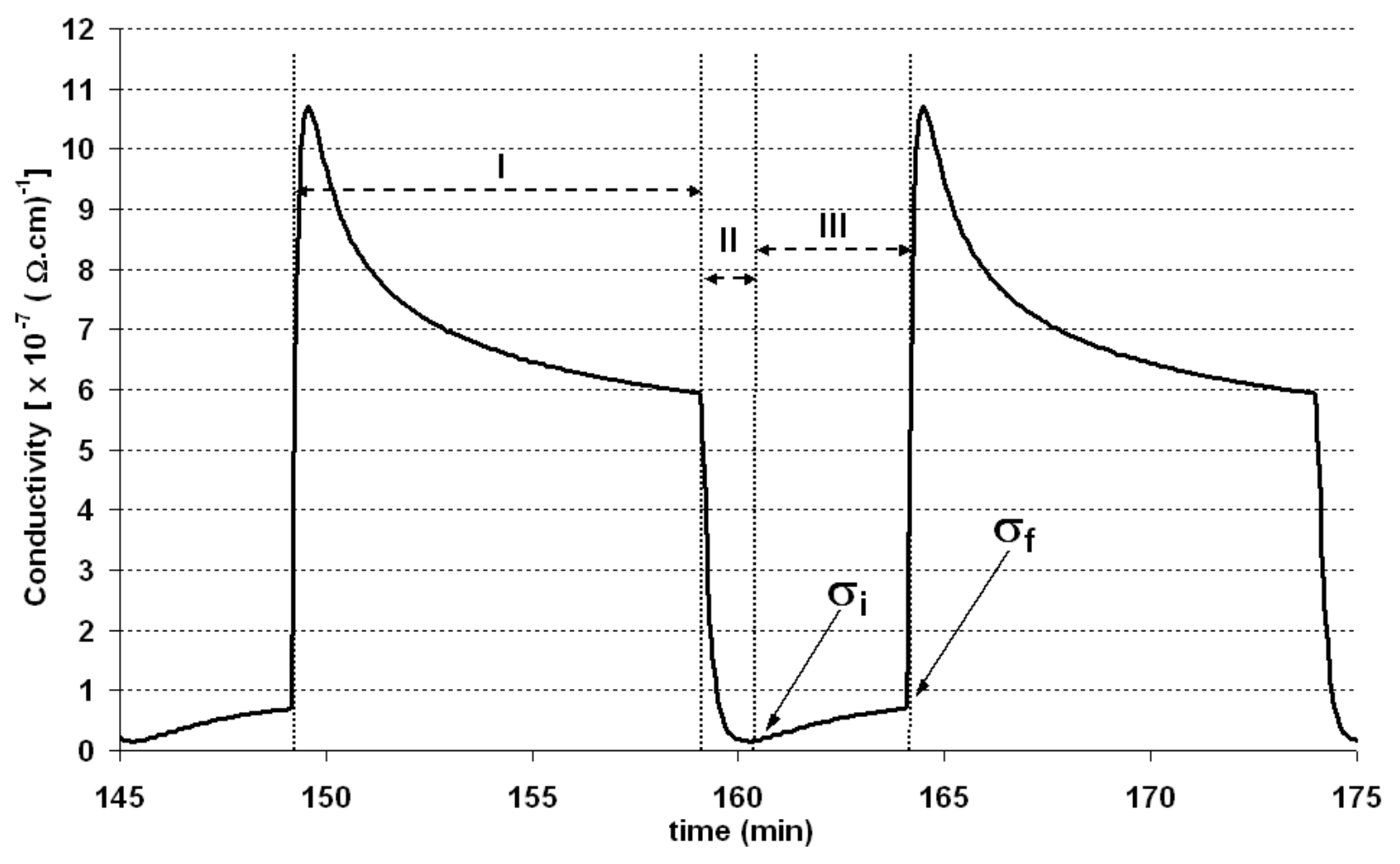

Fig. 3. 


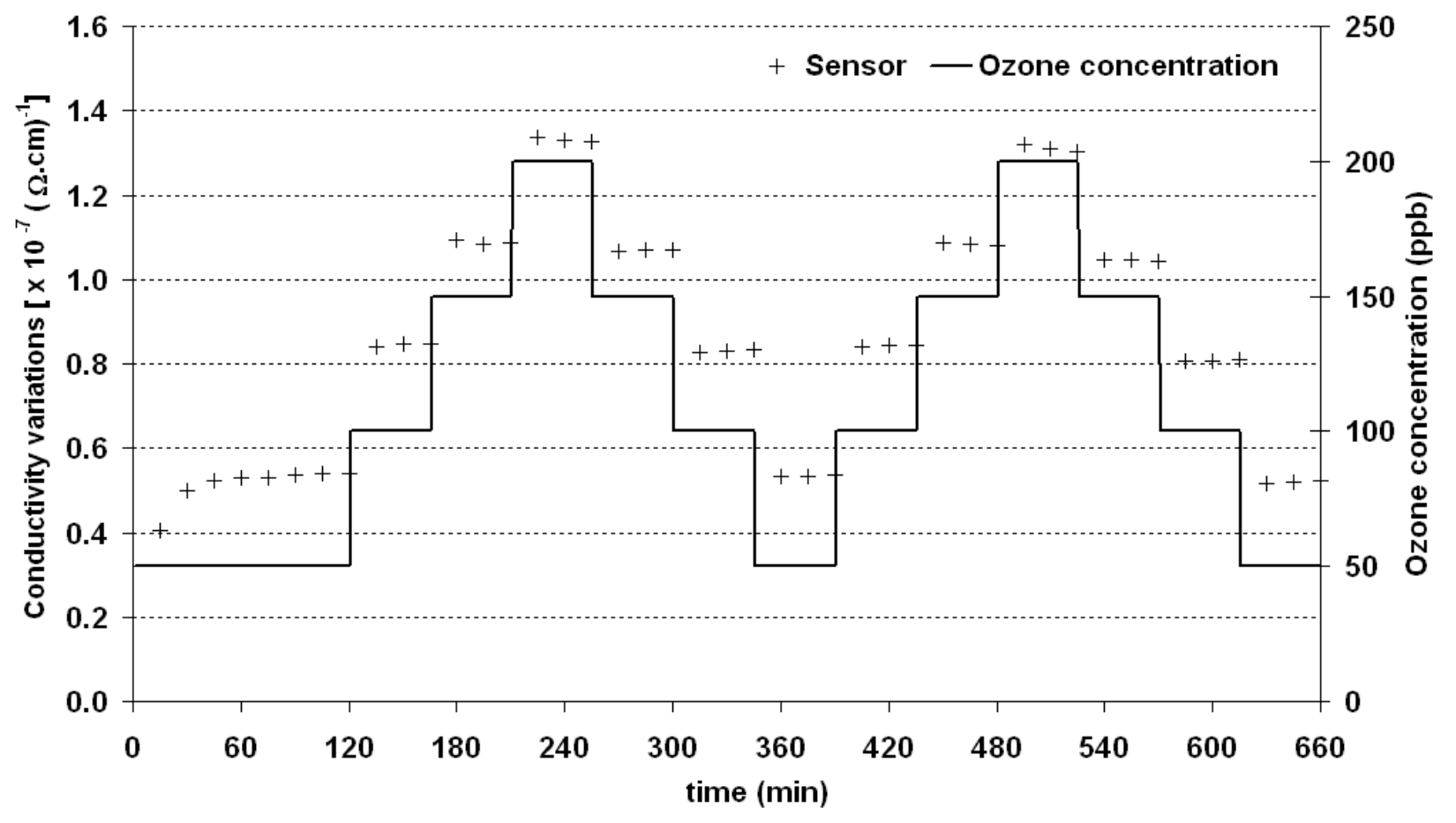

Fig. 4. 


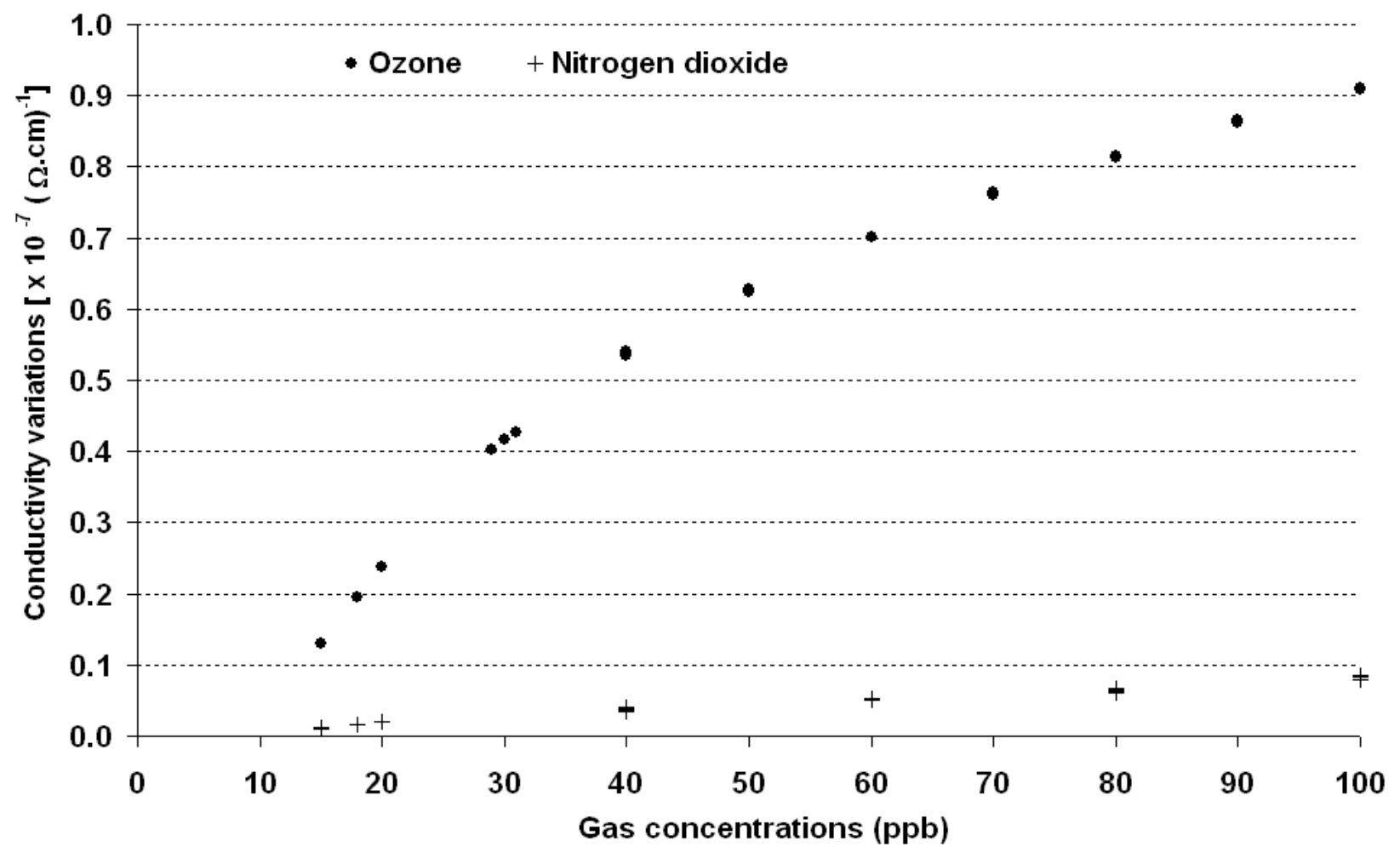

Fig. 5. 


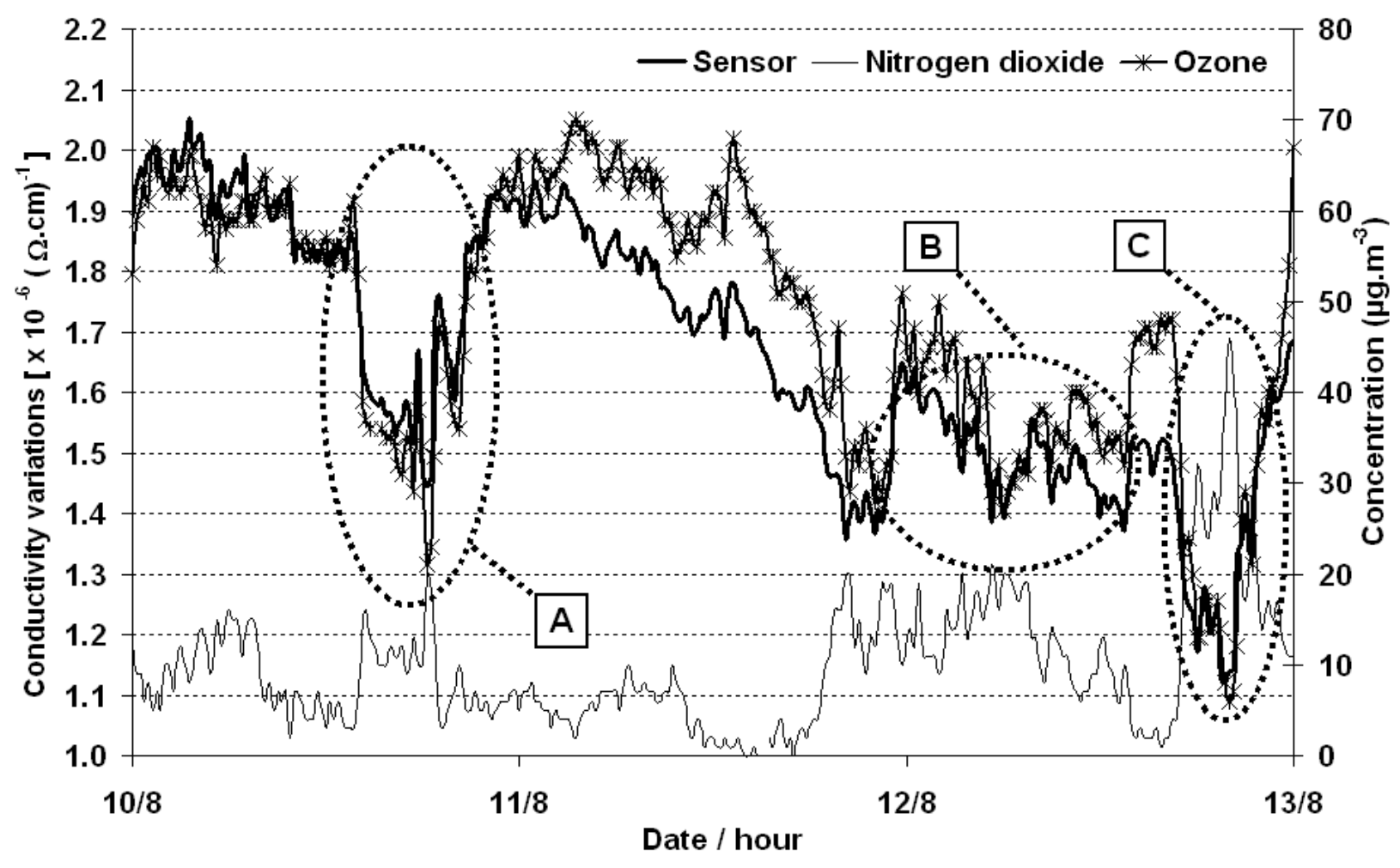

Fig. 6. 